\title{
TÚNELES LLENOS DE TIEMPO, TRAMAS LLENAS DE HISTORIA. LAS GALERÍAS COMERCIALES DE CONCEPCIÓN VISTAS EN EL AÑO 2010
}

\author{
TUNNELS FILLED WITH TIME, WEAVINGS FULL OF HISTORY. \\ THE COMMERCIAL GALLERIES OF CONCEPCIÓN SEEN IN \\ THE YEAR 2010
}

\section{RODRIGO HERRERA O.2}

\section{RESUMEN}

Las galerías comerciales del centro de Concepción recorren un tiempo y llenan un espacio en el transitar de la ciudad de Concepción del siglo XX. Hoy, situadas en un momento crítico, se vuelven objeto de reflexión y proyección interesantes de lo que es la propia sociedad penquista, de sus habitantes y sus anhelos. Aquí ofrecemos un par de ideas que pretenden contribuir a la discusión de su importancia y su futuro.

Palabras clave: Galerías, valor patrimonial, usos sociales.

\section{ABSTRACT}

The traditional commercial centers, specifically the ones named "galerías" of Concepción's downtown area, extend across time and fill a space in the day to day of the city of Concepción of the 20th century. Today, placed in a critical moment, they become

\footnotetext{
${ }^{1}$ El siguiente artículo expone resultados y reflexiones insertas en el marco del proyecto DiuCordinario "Explorando la trama oculta del centro penquista: el caso de las galerías comerciales en el Concepción actual", financiado por la Dirección de Investigación de la Universidad de Concepción, y llevado a cabo durante los años 2009/10. El proceso de investigación contó con la participación, además del autor del artículo, de los licenciados en Antropología UdeC Jennipher Salas, Sebastián Toledo, Roberto San Martín y Abraham Sandoval. Lo referido a continuación es un intento de síntesis ( $y$ 'coherenciamiento') de lo visto, oído y leído en relación a las galerías, pero también más que eso. Intenté ser un "testigo" del mundo de las galerías, asumiendo un rol de transeúnte-cliente exageradamente hablador. No obstante estas garantías, los sesgos incluidos en el trabajo de 'coherenciamiento' de la información son probables e inevitables y, ojalá, exculpables.

${ }^{2}$ Antropólogo, Departamento Sociología y Antropología Universidad de Concepción. Concepción, Chile. E-mail: rherrerao@udec.cl
} 
an interesting object of reflection and projection of what is unique to local "penquista" society, of its inhabitants and their longings. Here we offer a several ideas to contribute to the discussion of their importance and future.

Keywords: Commercial shopping centers, cultural heritage value, social uses.

Recibido: 11.09.11. Aceptado: 09.01.12.

\section{CUARENTA Y TANTAS GALERÍAS EN TAN SOLO 15 MANZANAS}

$\mathrm{P}$ ARTAMOS CON UN DATO que podríamos caracterizar como "objetivo": en el centro urbano de la ciudad de Concepción existe una gran cantidad de galerías comerciales. ¿Cuántas? Ahí la objetividad no logra ponerse totalmente de acuerdo, aunque se discrepa por poco: 46 para unos, 48 para otros, 43 para otros de más allá ${ }^{3}$. Es que pareciera que un catastro realizado el año 2009, por ejemplo, no tenga asegurada su veracidad para el 2010. Puede que entremedio alguna haya desaparecido, o que quizá haya nacido alguna nueva, o se fusionaran otras tantas. Quién sabe. Porque a lo largo del siglo XX surgieron varias en etapas sucesivas al parecer más o menos planificadas, pero su dinámica fue variable, nunca lineal, cambiando nombres, extensiones y existencias en ocasiones de formas más abruptas que otras.

Pero igual no cabe duda de que el dato “objetivo” es decidor, y más aún si le aplicamos un razonamiento ya del orden de lo cualitativo: hay muchas. Y eso debería ser indicador de algo... ¿pero de qué realmente?, o ¿es más un simple azar? En el fondo, ¿explica algo el que haya tantas? La pregunta es compleja posiblemente porque involucra diversos niveles, algunos de orden arquitectónico, otros urbanísticos, de todas maneras comerciales, y deberíamos decir que también del orden de lo sociocultural. Esto último tomando fuerza si atendemos a la iniciativa que CORBIOBÍO implementó

\footnotetext{
${ }^{3}$ Las fuentes de consultas sobre temas de esta índole remiten a la variedad y multiplicidad, por lo que enumerarlas a todas sería escribir otro texto. Están los reportajes periodísticos exhibidos en la prensa local, las memorias de titulación -principalmente de arquitectura- en las universidades locales, artículos varios que giran en torno a los temas urbanísticos de la ciudad y que mencionan al paso las galerías, páginas webs relativas a temas de arquitectura, novelas locales en las que se convierten en escenarios frecuentes, entre otras fuentes de consulta donde es posible seguir pistas mínimas en las que aparecen las galerías comerciales como referencias concretas, aunque nunca en forma exclusiva. Con esto, y aunque suene paradojal, se pone de manifiesto que las galerías comerciales penquistas no son un elemento de discusión frecuente en los diversos formatos literarios existentes (científicos, novelescos, periodísticos, etc.), aunque sí de alusión como al paso.
} 


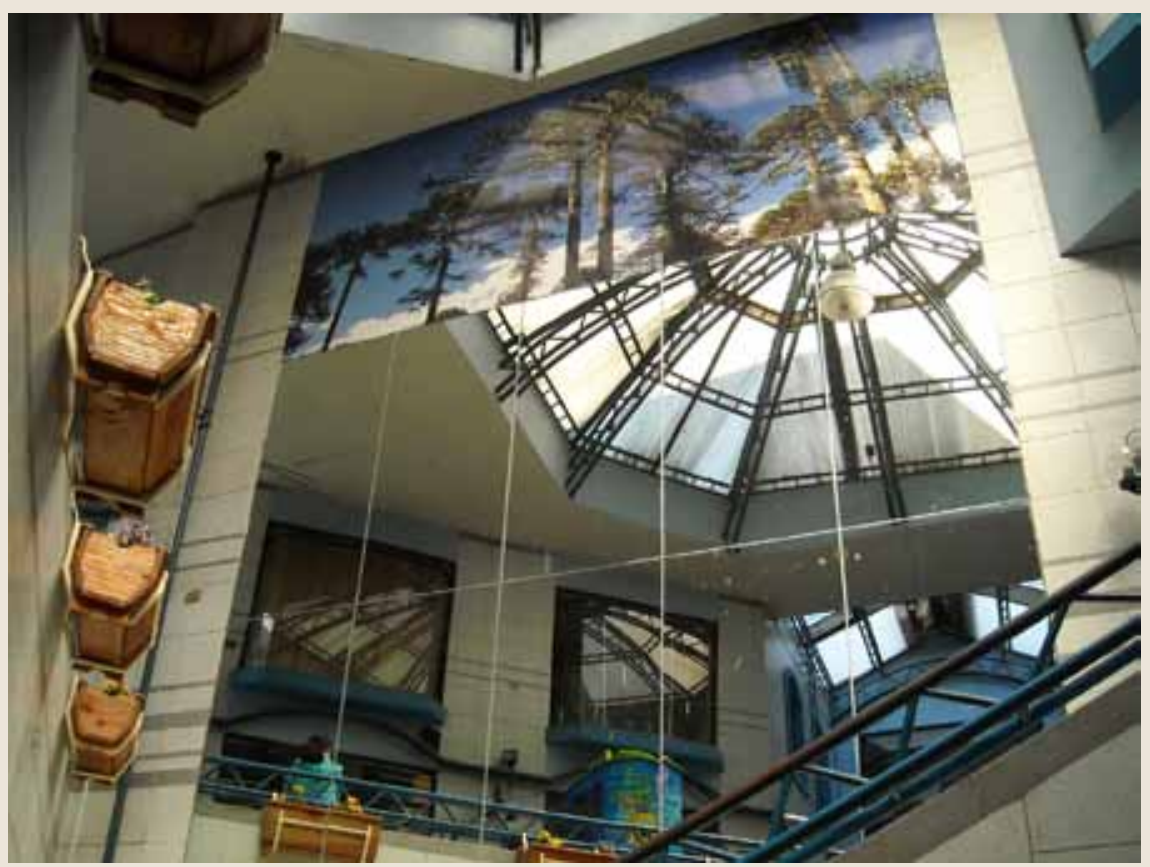

Figura 1. Galería Las Araucarias.

en el verano 2010 denominada "Ruta Patrimonial Galerías de Concepción", inserta en el proyecto "Reencántate con tu ciudad"4.

Igual hay que decir que no sólo es CORBIOBÍO quien ha mostrado ese interés en destacar un cierto "rol" que las galerías comerciales, casi sin querer queriendo, han terminado por cumplir dentro del contexto más global de la ciudad de Concepción en términos "patrimoniales" o "identitarios". Ciertamente están en boca de muchos, que las observan a la luz de un cierto decaimiento actual, enfrentadas a sus propios fantasmas de desorganización y divisiones internas, además de amenazadas por los malls que parecen dejarlas en el abandono, el olvido y sin "público". Al respecto, no es menor que frente a la posibilidad de acceder mediante entrevistas a las opiniones de una serie de profesionales que, de una u otra manera y más allá de su

${ }^{4}$ El diario El Sur publicaba el jueves 21 de enero de 2010 la siguiente información: “CORBIOBÍO dio ayer la partida oficial a la 'Ruta Patrimonial Galerías de Concepción', iniciativa enmarcada en el proyecto de Responsabilidad Social denominado 'Reencántate con tu ciudad', único en su tipo a nivel regional. CORBIOBÍO invitó gratuitamente a más de 50 jóvenes en riesgo social del Hogar Madre Adolescente, Aldeas SOS y otras instituciones bajo la tutela del Servicio Nacional de Menores. El recorrido histórico-cultural se enfocó en fomentar la identidad local...” 
profesión específica, "piensan" la ciudad desde su experiencia y sentimiento, el conjunto de los consultados refiera a las galerías como elementos que desde un principio singularizaron el centro y fueron otorgando a través del tiempo un "valor agregado" al mismo, no únicamente por su cantidad, sino también por su inserción dentro de una trama urbana no sólo material, sino también social y cultural, erigiéndose en verdaderos escenarios donde ha transcurrido parte de la historia de la ciudad 5 .

Asimismo, y quizá en relación a esto último, no hay que dejar de lado el hecho de que en una ciudad como Concepción, sin grandes resaltes arquitectónicos, urbanísticos o patrimoniales conservados y disponibles para ser utilizados o referenciados por sus habitantes, las galerías comerciales han venido a ocupar un espacio prácticamente vacío, ayudando sin duda a construir una imagen/discurso de ciudad -hoy casi obligatorio para toda urbe- necesaria para mostrarse al mundo, tentar a los potenciales turistas e indicarle a las otras ciudades vecinas lo que aquí sí hay y en otras partes no. En ese sentido, las galerías para algunos tienden a situarse como ámbitos de interés, tramas arquitectónicas que han alojado otras tantas tramas sociales, dejando postales del recuerdo, alusiones lejanas, casi sin querer, casi sin darse cuenta.

\section{LA CURIOSIDAD DE LOS ESPACIOS PRIVADOS DE USO PÚBLICO}

Ahora bien, si nos situamos desde la intención de hacer un recorrido por estas ideas que mezclan nostalgia con urgencia, sentimientos con eficiencia, quienes tradicionalmente se han acercado a la tentativa de dar luces en torno a las galerías comerciales del centro penquista son principalmente los arquitectos, observadores consumados de las formas construidas insertas dentro de un entorno que las acoge y recibe sus influencias. Y en función de ello podríamos señalar que han consensuado un par de percepciones que

\footnotetext{
${ }^{5}$ Las entrevistas, elaboradas y realizadas por el licenciado en Antropología Abraham Sandoval en el período comprendido entre abril y octubre de 2010 abarcaron un interesante y amplio abanico de voces que iban desde el expresidente de la Cámara de Comercio local Alex Cattán, el historiador y director del Museo de la ciudad de Concepción, Alejandro Mihovilovic; la curadora y encargada del archivo fotográfico del Museo de Historia Natural de Concepción Roxana Torres; el abogado y presidente de la Sociedad de Historia de Concepción Armando Cartes, el sociólogo del Centro de Estudios Urbano Regionales (CEUR) Rafael Galdames, hasta los arquitectos Leonel Pérez, Gonzalo Cerda, Jorge Harris y Roberto Goycoolea. Cabe señalar, no obstante, y como suele ser regla general derivada de la aplicación de las entrevistas, que, salvo alusiones textuales, las afirmaciones corresponden más a interpretaciones del autor que a alocuciones directas de los entrevistados.
} 
afirman su funcionalidad y podríamos pensar que promueven su continuidad. Al decir de Cerda (1991), por ejemplo:

La 'trama oculta' o la 'trama dentro de la trama' es una expresión que da cuenta de la red de galerías existentes en el centro penquista. Esta red, que interactúa con las calles tradicionales, permite el recorrido peatonal del área urbana central, prácticamente sin salir al exterior, salvo para cruzar la calle. Para una ciudad lluviosa y con la permanente presencia del viento como Concepción, ésta resultó ser una respuesta moderna perfectamente apropiada.

Dos son los elementos que claramente se resaltan: la protección climática que otorgan y su conexión con las calles, pero protegidas también de los autos. En eso Pérez y Espinoza (1998) son también enfáticos, pero además le agregan la estrecha vinculación entre su desarrollo y otros intereses típicos de planificación urbana como el aprovechamiento del suelo urbano, escaso siempre por casi decreto de la naturaleza:

La galería comercial se define por la penetración de las veredas a la calle interior de la manzana, siendo su principal rol el ser un espacio de circulación peatonal que acoge una actividad comercial. Las galerías o trama oculta, conforma ejes de circulación peatonal. Producto del crecimiento del comercio a fines del siglo pasado, se planteó la necesidad de maximizar el uso del suelo central de las manzanas, independizándose de la circulación vehicular y protegido de los factores climáticos.

O sea, protección climática, seguridad al peatón y además densificación del centro dentro de marcos comerciales porque abren el interior de las manzanas, ocupándolo a través de pasillos, vitrinas y luces de neón. Interesante. Se entiende también entonces su surgimiento allá por los principios del siglo XX (La Moliat-Lamoliatte para otros-, en el actual emplazamiento de la galería Musalem) y su continua aparición a partir de allí hasta el año 2009 (Galería Italia), conformando un conjunto que en palabras de Camacho (1986) constituyen:

un sistema de circulación peatonal autónomo que se ha desarrollado en el tiempo en un forma silenciosa auspiciada por el sector privado, adquiriendo en los últimos tiempos una importancia vital dentro del sistema urbano... (1)

Por ello: son funcionales a diversos intereses, económicos, urbanísticos, 
climáticos, etc. Y así también en que se conforman como alternativas de circulación, opciones para cruzar "a través", cuales paseos públicos. De hecho, se ha tendido a caracterizarlas como paseos públicos de invierno, enfatizando su adaptabilidad a un entorno geográfico y su clima. Pero el tema es que no son del todo paseos públicos, son "casi". Como todo lo que guarda relación con el comercio en nuestro mundo moderno, están protegidas, por las noches cierran sus puertas con candado, desplazando su condición de "alternativa de circulación" hasta que salga el sol nuevamente. En el día, acogen; por las noches sólo silencio. Será por ello que la nomenclatura más técnica nos indica que:

En términos legales la galería comercial es un espacio cubierto destinado al tránsito peatonal de propiedad privada de uso público, creado individualmente con fines comerciales... (Camacho 1986: 2).

Pero el tema es que sus alcances no acaban en su condición jurisdiccional o administrativa, o digamos que más allá de las funcionalidades y consideraciones legales, en palabras de Martínez (2006: 21), las galerías:

A pesar de que su rol fundamental es el comercio, para el habitante común son refugios de la lluvia, el viento o el sol, formas de acortar camino o vías alternativas y lugares de encuentro, actos que aún no estando relacionados intrínsecamente con el comercio son los que le dan vitalidad urbana al centro de Concepción, pues posibilitan el contacto y el enriquecimiento del habitante de la ciudad...

En síntesis: que si bien la función primera de las galerías está ligada a su condición de respuesta histórica frente a necesidades urbanístico-comerciales, su completa apertura diurna a quien quiera ingresar en ellas y su conformación a manera de diversos túneles interconectados que cruzan el centro penquista, les acaba por dar un valor adicional de índole netamente social, relativo al orden de las relaciones sociales que allí se acogen, se despliegan, se entrelazan. Pero además esta valoración acaba por contagiar a ese entorno conformado por el centro de Concepción, volviéndolo también a él particular, exclusivo, central en los términos que el sociólogo $\mathrm{H}$. Lefebvre (1969) le otorgó en tanto referencial, atractivo, revuelto, sobre-expuesto. Porque este centro son, en una importante medida, sus galerías en tanto puntos de fuga que llaman a lo no planeado, al desvío del camino, a la posible improvisación dentro de un marco donde todo se revuelve, pero a baja intensidad. Las bocinas, sirenas y discursos protestantes se apagan 
para dar paso a los murmullos, guitarreos y rumores que sólo se apagan por la noche.

Y es en esta lógica de las superposiciones situacionales y emocionales del que se nutre ese espacio donde se situaría el mayor atractivo de las galerías, al acoger relaciones variables y variadas; simultánea y regularmente; siguiendo la lógica de lo imprevisto, pero también de lo esperable y rutinario. Funda su dinámica un espacio social simmeliano, que es más el resultado de las relaciones que lo agitan atravesándolo, que de los órdenes pensados y planeados al crearlas. Porque una cosa fue su concepción, su plano en el papel, pero otra su uso, aquel caudal de actividades prácticas que sus diferentes usuarios despliegan para "apropiarse" de esa morfología provista. Y entonces durante el día, en horario de comercios abiertos, las galerías asumen el rol de espacios urbanos que se definen en la mixtura pendular, ya realzando relaciones del orden de lo íntimo y la familiaridad cotidiana entre quienes se conocen y re-conocen, ya abundando en referencias que nos permitirían hablar de la condición pública de esos espacios sociales, en los que la impersonalidad y radical exterioridad de los presentes marcan la estructuración de la sociabilidad.

Un ejemplo claro de esto que señalamos lo constituye la dinámica cotidiana de la galería Musalem (junto a su par galería Zaror), con sus tiendas de ropa en cajones y otras con mayor diseño, música de todos los tiempos, cachivaches varios y su cafetería-sandwichería-schopería, no precisamente ubicada en el centro exacto de la galería, pero de una $u$ otra manera ocupando un lugar referencial en su dinámica. Ubicada además en uno de esos puntos de mayor nerviosidad de la ciudad, en sus interiores es posible ver diversos tipos de relaciones, aproximaciones, rutinas y usos por parte de locatarios, dependientes, clientes, transeúntes u otro tipo de usuarios. $\mathrm{Y}$ todo va desde la mayor familiaridad que pueden demostrarse locatarios vecinos, dependientes de locales distintos pero de dueños similares, o cargadores de mercadería que pasan por la cafetería-sandwichería-schopería a saludar, pasando por el tránsito lento de vendedores ambulantes o más rápido de transeúntes variados, hasta llegar a los "lanzas" que de vez en cuando cruzan como ráfagas de viento por los pasillos seguidos por policía motorizada que a punta de frenadas y chirridos logran con mediano éxito salir del laberinto por alguna de sus cinco aperturas.

Adentrándose en la rutina de esta galería uno puede acabar construyendo una clasificación que daría cuenta de un cierto agrupamiento de relaciones escenificadas, aunque nunca conociendo de antemano el orden cronológico de su desarrollo. Es decir, su potencial dinámica de sociabilida- 
des apunta hacia el infinito, aunque finalmente el despliegue de las relaciones dadas acaba por delimitar patrones de interacción finitos que revelan mayor o menor familiaridad, mayor o menor rutinidad, mayor o menor formalidad, mayor o menor distancia social para hacer frente a la cercanía física. La galería Musalem conforma entonces un espacio arquitectónico que fomenta "escenas" de vida pública y privada, de encuentros y desencuentros, donde, al decir de D. Harvey, la armonía nace del enfrentamiento de las diferencias. Es un espacio conflictivo, de visibilización de conflictos, pero que ofrece también continuas maneras de resolverlos, generalmente sin alterar el pacto de la baja intensidad.

\section{LAS COMPLEJIDADES DE SU ACTUALIDAD}

Ahora bien, no obstante estas constataciones, curiosamente hemos de testimoniar un discurso pesimista y cansado que se erige desde adentro y afuera en torno al futuro de las galerías, donde también se incorpora su presente. No es claro su origen ni su sistema de difusión, pero permea conversaciones con locatarios de las mismas, reportajes periodísticos en los que se le otorga voz a representantes de la administración de la ciudad y a urbanistas a los que se recurre como expertos, y opiniones de pie de calle hechas al pasar sin mayor aspaviento.

Tampoco es posible establecer de forma taxativa que el nacimiento de esta mirada negativa coincida con su aparición, pero es inobjetable que hoy por hoy se entiende que las galerías tienen un enemigo declarado: los malls (que en Concepción apareció -en singular- el año 1995). Este discurso incorpora elementos varios: económicamente el mall le quitó clientes al comercio de galerías; arquitectónicamente, los malls vienen a representar una suerte de paso en falso estético en relación a su inserción en el paño urbano; socialmente, su llegada deja vacío el centro de aquel conjunto de relaciones urbanas que más lo dinamizaban y hacían atractivo.

Su derrotero más menos seguiría la siguiente lógica: habría una secreta o cuasi invisible línea recta con un claro trasfondo evolutivo que indicaría que los malls han acabado por reemplazar a las galerías al adaptarse mejor a los nuevos requerimientos y patrones del consumo, modificando de paso no sólo las condiciones del mercado de compra y venta de productos y servicios al detalle, sino también modificando radicalmente los patrones de conducta del consumidor en la sociedad chilena. Acogiéndose a esto, se entiende que las galerías han cumplido una etapa y vendrían a ser representativas de un tiempo y una sociedad del pasado, época en la que efec- 

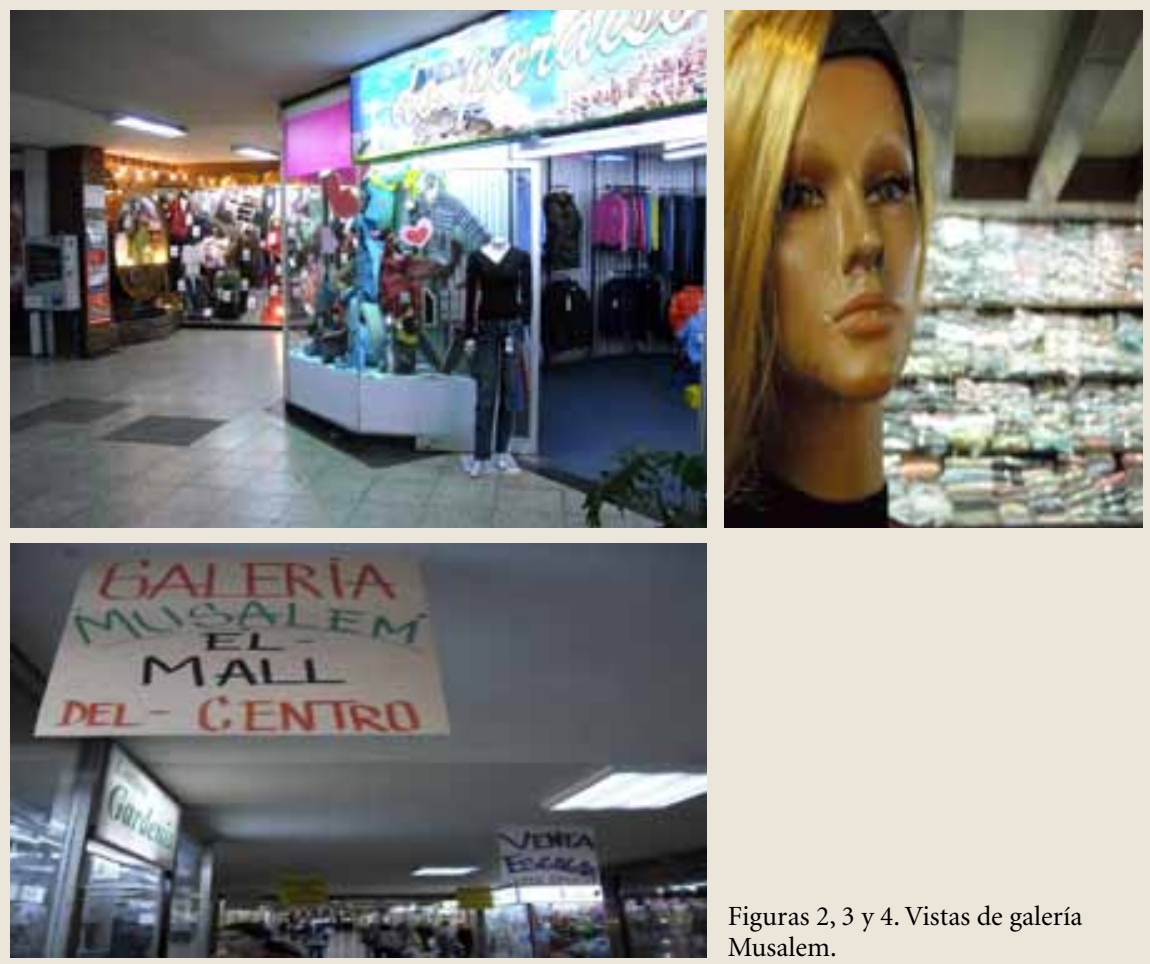

Figuras 2, 3 y 4 . Vistas de galería Musalem.

tivamente no sólo habrían logrado erigirse como soluciones urbanísticocomerciales, sino que también, por ese éxito, habrían alcanzado una cierta centralidad al acoger personas, grupos y gentes diversas que allí se juntaba, se encontraba, se reunía o se escabullía.

En términos prácticos, estamos recorriendo un siglo de historia de las galerías. Entendiendo que alrededor de los años 40, dentro del marco de la primera gran reconstrucción en clave moderna de un posterremoto, comienzan a surgir con mayor asiduidad dentro de contextos más planificados, y también en reemplazo de los viejos portales que a la fecha existían. Después, y debido a la buena acogida y funcionalidad de estos verdaderos ensanches de calzada, durante los años 60 y 70 , y en el contexto de otro gran programa de reconstrucción posterremoto, viven un momento de apogeo, ya abarcando manzanas enteras por las que filtrarse y acogiendo diversidad de funciones (cines y cafés como émbolos de puntos de reunión), hasta llegar a los 80 donde surgen una que otra, y los 90 que viven un repunte al mismo tiempo que ven surgir su amenaza allá lejos, en los arrabales de la ciudad. 
De acuerdo a este esquema, se interpreta como un aviso previo de los cambios que se venían el Centro Comercial Caracol, creado en 1980, o el Paseo Boulevard Gascón, de 1978, adaptaciones de aquella lógica inicial de las galerías como ocupaciones lineales de la manzana interior a nuevos formatos en los que, por ejemplo, la arquitectura del lugar no sólo delimitaba un pasillo que cruzar, sino todo un paisaje a recorrer por sí mismo, en lo que podría entenderse como la antesala del mall. De alguna manera, veríamos que desde la emblemática galería Alessandri (1945), reconocida como el primer gran túnel erigido como galería, que no obstante ya era ocupado como tal antes de su "urbanización", pasando por la paulatina conjunción que deriva en el conjunto Universitaria (1958) / Ramos (1958) / Montserrat (1964) / Banco Español (1977), hasta llegar al mencionado Caracol, hay formas en adaptación, acomodamientos más o menos planificados del como maximizar la ocupación del suelo. Igual si, por ejemplo, seguimos la fisonomía adquirida por la conjunción -o "sistema de galerías"- de las galerías Martínez (1940) / Rialto (1952) / Las Araucarias (1992), donde se juntan propuestas y fisonomías variadas que hablarían de épocas, tendencias y gustos y que acaban por otorgar una larga continuidad espacial, basada paradójicamente en la discontinuidad de luces, olores, gentes, vitrinas, etc.

Pero es esta misma condición de surgimiento escalonado, pero no demasiado organizado, de las galerías lo que este discurso más pesimista acaba por enfatizar como negativo o problemático. Lo que podría entenderse como una virtud -la sobreposición estimulante- acaba por ser leído en clave "desorden" o "incoherencia", que acabaría teóricamente alejando a la gente. Dado este panorama, se piensa que las galerías o se reinventan o desaparecen en el corto plazo, devoradas por la aplanadora de las nuevas exigencias del consumidor que ha escogido ya y se ha inclinado por las palmeras interiores y exteriores, la luz artificial homogénea y el orden claro y legible de locales comerciales que exhiben lo que revistas y tv previamente ofrecen. Esta tensión cobra plena vigencia actualmente con la amenaza del pronto arribo al centro penquista del "mall del centro", cuyo nombre parece querer remitirnos a toda una declaración de principios detrás de la propuesta comercial. Y entonces el rumor que se escucha de vez en cuando por los pasillos de las galerías alude a una tensa espera del momento en que la maquinaria arranque y vacíe de personas las galerías, aleonados todos por este nuevo formato más cómodo, más práctico, más aséptico que esconde el concepto "mall". Y mientras tanto, agonizamos.

Ni siquiera el agregado romántico que imagina las galerías como verdaderos refugios de un pasado esplendoroso tejido alrededor de cines, pequeñas tiendas referenciales y aglutinantes o cafés de rincones, parece ser 
la tabla de salvación. Porque los cines ya se fueron, se habían quedado aparentemente sin público, las tiendas referenciales ya no son las mismas y las que hay están precisamente en los malls y los cafés salieron a la luz natural ofreciendo reductos climatizados con grandes ventanales para ver y ser vistos profilácticamente. O sea, siguiendo esta lógica evolucionista lineal, las galerías posiblemente "fueron" refugios, espacio o lugares donde acontecieron cosas importantes, pero ya no. Y, entonces, pocos están muy dispuestos a defenderlas en ese plano.
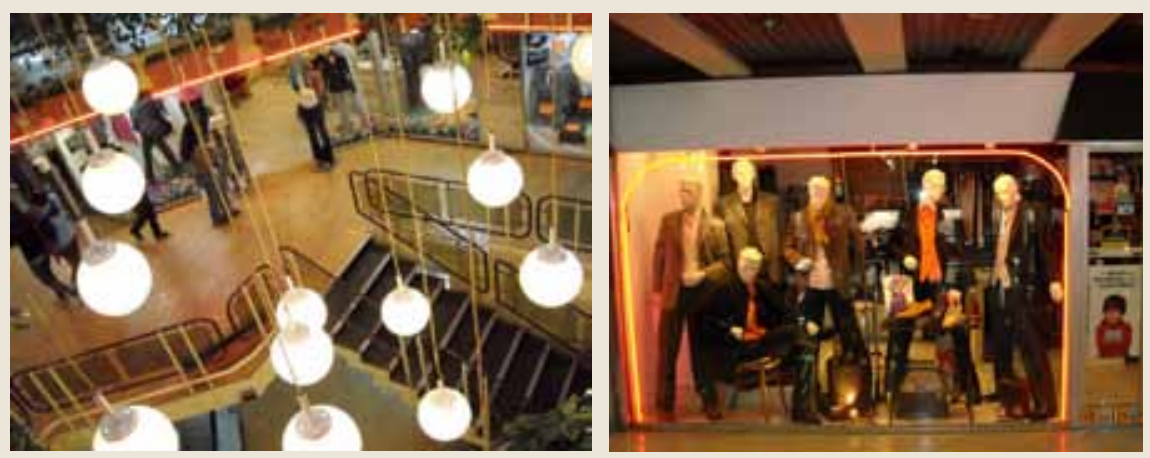

Figuras 5 y 6 . Interior galería Boulevard Gascón.

\section{EL VALOR DEL USO}

Donde sí se han podido escuchar voces reivindicativas es en su asociación urbanística al tan desvalido concepto de identidad. Allí las galerías crecen, su vuelven importantes. Ello porque se constituyen como referentes de identidad urbana y, por derivación, de identidad penquista. Las galerías serían algo así como un ícono oculto a simple vista, misterioso en su entramado confuso, y que sin embargo conectaría con las entrañas de lo penquista. No visibles inmediatamente, no conocibles o reconocibles en su totalidad de inmediato, sino que develadas a partir de las pausas y el entrenamiento del ojo, acabarían por hablar y exhibir el pasado de una sociedad que encarnó ciertos valores de la urbanidad entre sus pasillos y sus rincones, en sus zonas de luz y sombra. De hecho, en la elaboración de este discurso identitario cobra especial fuerza la condición "importada" del modelo comercial de los malls, el que vendría acompañado de modelos de comportamiento social que estaría acabando con todo un modo de habitar y de hacer ciudad. 
Desde este punto de vista, se habla del valor patrimonial de las galerías comerciales, lo que viene a ser algo así como la abstracción de un reducto imaginario en el cual se pretende alojar un conjunto de prebendas de índole emocional que reflejen algo que previamente se ha establecido, se quiere conservar de la erosión que inflige el tiempo a todo lo humano. Así, a través de este ejercicio, algunas cosas sueltas de las galerías se deberían rescatar, organizar y, presumiblemente, predisponer para ser exhibidas en el imaginado museo de la identidad penquista. Algo así está detrás de la labor ya mencionada que realizó CORBIOBÍO durante el verano 2010, abocada a rescatar y/o destacar aquello que la propia ciudad les debe, casi como buscando restituir esa tradicional alianza beneficiosa para ambas que se ha conformado entre el centro de la ciudad y las propias galerías.

Lo positivo de esta tendencia es que una vez más ratifica que las galerías, casi sin querer queriendo, se han transformado en algo más que su funcionalidad adscrita a la protección climática, seguridad al peatón y aprovechamiento del suelo urbano del centro. Se asume que han compuesto espacios sociales de participación y apropiaciones variadas y variables, emplazamientos donde se ha desarrollado parte importante de la vida social del Concepción de la segunda mitad del siglo XX, allí donde varios se han conocido, reconocido, simplemente oteado o hasta ninguneado. Y no sólo aquel selecto grupo de los comerciantes locales que las pensaron y edificaron, sino que todo aquel que por allí circulaba tenía la oportunidad de asistir a una pequeña representación de la vida social de la ciudad. Y ello se valora y se busca recordar.

Pero allí también surge la legítima duda de ¿qué es lo que se quiere rescatar? Porque el discurso que las reivindica en tanto refugios de identidad -o sea de valores y sentimientos colectivos "propios"- surge junto con aquel que las hace aparecer desvalidas, supuestamente caídas en desgracia y vaciadas, aunque muchas de ellas cada día igual estén repletas de gente circulando y usándolas. Se habla de que los comerciantes están preocupados por su futuro, no obstante los locales en arriendo permanecen poco tiempo libres y su precio no decae. Se dice que con el mall del centro les llegará su hora definitiva, sin embargo no se piensa cuánto de la lógica de las galerías habrá de incorporar éste para no transformarse en un elefante blanco. Se les aconseja reiventarse, por ejemplo a través de su tematización, olvidando que uno de sus mayores atractivos es su capacidad de desviarnos a través de la multiplicidad. Y, por último, se enfatiza su deterioro como razón de su necesaria intervención, olvidando quizá que en realidad no son un mall. 


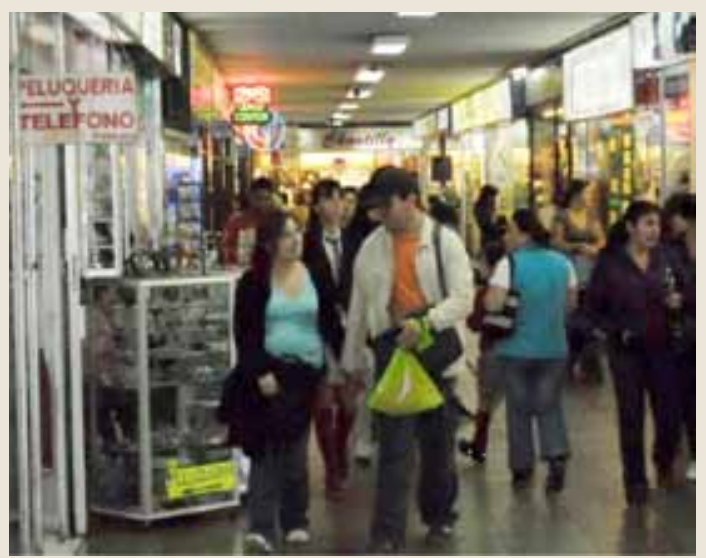

Figura 7. Interior galería Martínez.

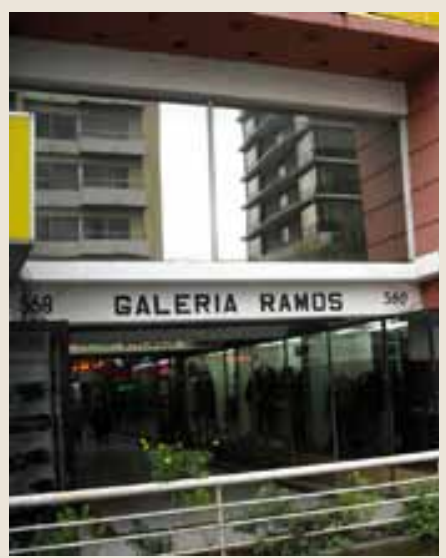

Figura 8. Uno de los ingresos a galería Ramos.

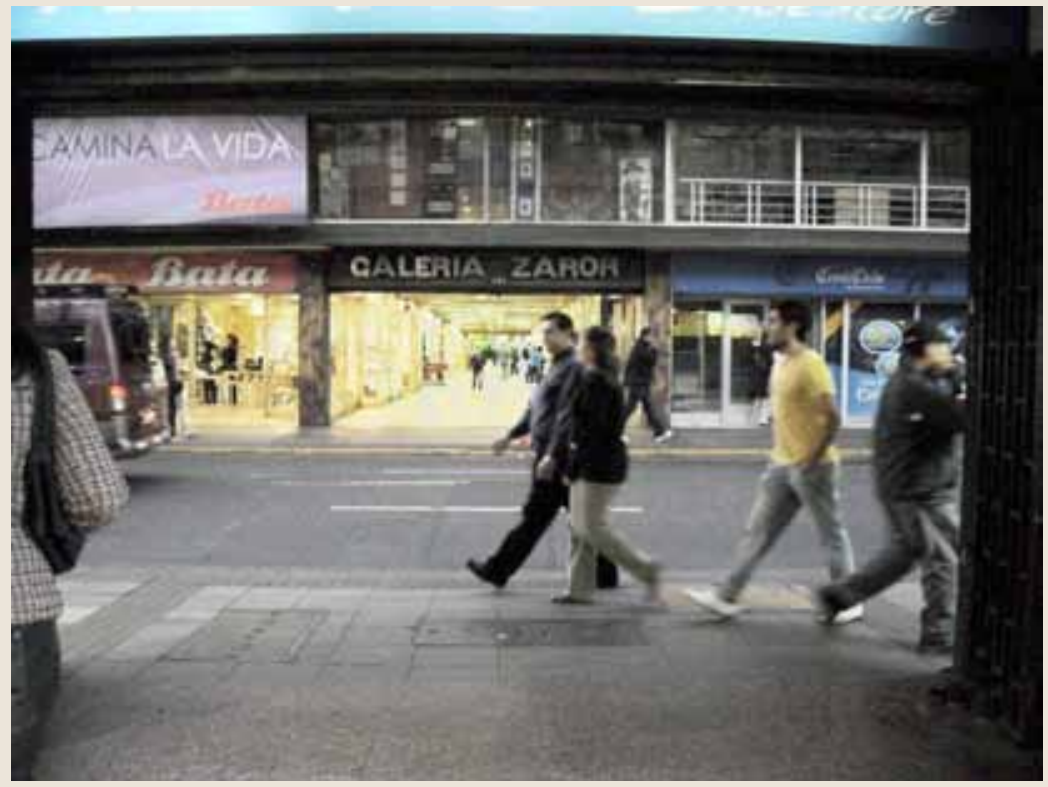

Figura 9. Salida galería Montserrat. 
Pareciera que se las quiera rescatar de todo aquello que las vuelve triviales, mundanas, vulgares reductos sin mayores atributos contemporáneos en las que se han convertido por obra y gracia del tiempo, y que en tanto tales no pierden su continua y sostenida afluencia de gente que ya acortan camino, ya se dejan llevar por el influjo del túnel, ya entran un rato mientras esperan locomoción colectiva o quedan de encontrarse con alguien en un lugar que no sea "la para' del tonto" a un costado de la plaza de la Independencia. Donde los pequeños cafés subsisten casi como salas de espera de despachos en los que se habla bajo y se gesticula sólo lo necesario. O donde se puede recurrir a un sastre, notario, zapatero, peluquero/a, enmarcador/a de cuadros, vendedor/a de telas, de cassettes, artículos sexuales varios, películas porno, ropa o tazones con motivos propios, libros y revistas del año que le pidan, autos de fricción, pizarras para dibujar, cargadores de celulares de todo tipo, cocadas, cuchuflíes, flores artificiales, alfombras, ropa de segunda selección, entre otros miles de artefactos, productos o rubros.

Es el peligro del discurso patrimonial que rescata pero a costa de descontextualizar, sacar del tiempo un espacio que se debe a él y, con ello, alejarlo de su principal valor agregado: sus usuarios. Es el peligro de lo que se institucionaliza, pero que, al hacerlo, vuelve sus espaldas a la acción humana, a su intervención por parte de quienes lo deseen respetando los códigos implícitos, en este caso, de la baja intensidad. Es un discurso que disciplinas de las ciencias sociales como la antropología conocen bien: el del rescate moral a través de la patrimonialización. Porque en la pregunta de ¿qué es lo que se quiere rescatar?, se pierde la ingenuidad y la inocencia. De ahí que una reivindicación lógica como puede ser intentar que escenarios de sociabilidad como las galerías comerciales del centro penquista no desaparezcan, planteada en estos términos corre el serio peligro de que se institucionalicen en nombre de quién sabe qué valores superiores ciertas prácticas y saberes como propios de un mundo que se cree en retirada, sin claridad de la diversidad de factores y dinámica de lo que sí en la práctica compone el juego.

Las galerías entonces podrían acabar asimilándose a verdaderos museos de valores urbanos perdidos en algún temporal, descontextualizadas y alejadas de quienes son su principal valor: sus usuarios. Porque justo lo que se quiere reivindicar no es lo que hacen de ellas quienes las usan, porque precisamente lo que se quiere rescatar aleja la idea de apropiación por parte de gente que trabaja, deambula o transita por ellas y las vuelve de esa manera algo necesario. 


\section{REFERENCIAS}

Camacho, A. (1986). Galerías comerciales en Concepción. Seminario de Título, Arquitectura, Universidad de Bío-Bío. Concepción, Chile.

Cerda, Gonzalo (1991). "Primera modernidad urbano-arquitectónica en el sur de Chile. El caso de Chillán y Concepción”. Disponible en: www.rafaellopezrangel.com [Consulta: 13.06.11].

Lefebvre, H. (1969). El derecho a la ciudad. Barcelona: Península.

Martínez, A. (2006). Galerías comerciales. Elementos de la identidad urbana de Concepción. Seminario de Título, Arquitectura, Universidad de Concepción. Concepción, Chile.

Pérez Bustamante, Leonel y Espinoza, L. (2008). Planificación urbana y espacio público en Concepción (1940-2004). Concepción: Editorial Universidad de Concepción. 